\title{
PENHORA DE VALORES: A APLICABILIDADE DO SISTEMA PERANTE O PRINCÍPIO CONSTITUCIONAL DA DIGNIDADE DA PESSOA HUMANA
}

\section{GARNISHMENT OF VALUES: THE APPLICABILITY OF THIS SYSTEM IN FACE TO THE CONSTITUTIONAL PRINCIPLE OF THE HUMAN BEING DIGNITY}

\section{Gabriela Zucatti Büttner ${ }^{1}$}

Resumo: O presente artigo possui como objetivo a análise da aplicação do sistema Bacen Jud a fim de efetivar a restrição de valores, admitida pelo Código de Processo Civil e a Constituição da República Federativa do Brasil, em confronto com a observância do princípio constitucional da dignidade humana. Ele visa explorar o avanço das tecnologias onde se possibilitou que houvesse maior celeridade na efetivação de restrição de valores, sendo esta a primeira opção de garantia processual prevista no art. 835 do Código de Processo Civil. Por outro lado, embora o uso do sistema Bacen Jud, feito através de comunicação instantânea aos bancos e cooperativas, seja importante, vem à tona a questão da ponderação e da mo- deração de seu uso, uma vez que o uso indiscriminado do sistema pode gerar interferência na esfera íntima do sujeito no que tange à dignidade dos direitos humanos e fundamentais. Analisa-se, ainda, o art. 833 do Código de Processo Civil, que apresenta o rol de impenhorabilidades no caso de valores a fim de garantir uma execução menos onerosa ao executado na solução da lide. Assim, pretende-se demonstrar que a tecnologia é nossa aliada, mas é fundamental que sejam resguardados os direitos e garantias individuais e coletivas previstas na Constituição e em nosso ordenamento brasileiro

Palavras-chave: Execução. Penhora online. Princípio da dignidade humana. Bacen Jud. Impenhoráveis.

1 Pós-Graduanda de nível de especialização em Direito Público e Privado pela Escola Superior da Magistratura do Estado de Santa Catarina (Esmesc), orientada pelo Professor Doutor Cristhian Magnus De Marco, PhD. Graduada em Direito pela Universidade do Oeste de Santa Catarina (Unoesc), campus Joaçaba. Técnica Administrativa Municipal de Joaçaba cedida para exercer as funções junto ao Fórum da Comarca de Joaçaba. Conciliadora voluntária no Juizado Especial da Comarca de Herval d'Oeste/SC. E-mail: gzbuttner@gmail.com 
Abstract: The purpose of this article is to analyze the application of the system Bacen Jud, admitted by the of Brazilian Code of Civil Procedure and the Brazilian Constitution, in order to assure the restriction of values, confronted by the observance of the constitutional principle of human dignity. It aims to explore the increase of technologies which make possible to accelerate the implementation of value restriction, once it is the first procedural guarantee option according to the article 835 of the Brazilian Code of Civil Procedure. On the other hand, although the use of the Bacen Jud system, made by instant communication to banks and cooperatives, is really important, it is a relevant matter the restriction and moderation of this system use, once the indiscrimi- nate use of this system may originate serious interference in the intimacy sphere of a person, when it comes to the dignity of a person and human and fundamental rights. It is also analyzed the article 833 of the Brazilian Code of Civil Procedure, which presents the list of non-earning garnishments, in order to assure a less onerous garnishment in the solution to the conflict. This way, it is intended to demonstrate that technology must be an ally, but it fundamental that the individual and collective rights and guarantees, provided by the Brazilian Constitution and by the Brazilian legislation, are observed.

Keywords: Execution. Online Garnishment. Principle of the Dignity Human. Bacen Jud. Unachievable.

\section{INTRODUÇÃO}

O judiciário encontra-se em pleno desenvolvimento tecnológico e constante aperfeiçoamento técnico com o objetivo em comum de atender aos anseios sociais decorrentes do dia a dia em sociedade.

Pois bem, o uso de novas tecnologias é cada vez mais bemvindo na atividade jurídica brasileira. Para efetivação desses recursos em realização de penhoras, o nosso ordenamento normatizou acerca da ordem preferencial a ser observada, por meio do art. 835, inciso I, do Código de Processo Civil onde preferiu de forma inicial, pela penhora de "[...] dinheiro, em espécie ou em depósito ou aplicação em instituição financeira" (BRASIL, 2015) a fim de garantir os processos.

A primeira parte deste artigo explicará acerca da forma em que é realizada a restrição de valores pelo judiciário brasileiro. Procurará demonstrar quais foram os avanços no meio utili- 
zado para realizar a busca por numerários bancários a fim de resguardar os processos e iniciará o a questão que incide na esfera individual da parte atingida pelas constrições.

Demonstrará a origem da aplicação do sistema Bacen Jud no meio jurídico feito por meio de um convênio firmado entre o Conselho Nacional de Justiça e o Banco Central, em 08.12.2008. Ainda, avaliará quais os princípios que regem e protegem o uso de avanços tecnológicos no meio jurídico, sendo alguns deles os princípios da economia e da celeridade processual.

A segunda parte do presente trabalho, tratará das consequências do uso do sistema Bacen Jud bem como da celeridade e economia nas ações do judiciário. Retratará a interferência da penhora de valores na vida do indivíduo e qual a importância da observância das impenhorabilidades apontadas no Código de Processo Civil aliado à aplicação do princípio constitucional da dignidade da pessoa humana.

Demonstrará que, ao serem realizadas as constrições pelo sistema, não é possível vislumbrar a origem dos valores, que podem ter origem impenhorável. Ao serem penhorados valores considerados impenhoráveis pelo art. 833 do Código de Processo Civil, configura-se uma invasão na esfera íntima do indivíduo ferindo as suas garantias individuais.

Assim, o presente trabalho visa estudar o equilíbrio entre o uso da penhora de valores pelo sistema Bacen Jud em face do Princípio da Dignidade da Pessoa Humana, tendo em vista que se busca uma execução que seja mais célere, econômica e ao mesmo tempo eficaz sem ser onerosa às partes.

\section{DOS PRINCÍPIOS PROCESSUAIS: DA ECONOMIA E DA CELERIDADE PROCESSUAL}

A crescente demanda processual requer o auxílio das novas tecnologias para facilitar o deslinde administrativo na busca 
de efetividade jurisdicional a fim de garantir um processo de duração razoável e satisfação dos jurisdicionados.

Sobre princípios, podemos entender que são diretrizes, bases, fontes criteriosas de inspiração às normas positivadas típicas de todo o sistema legislativo. Essas diretrizes norteiam a aplicação da norma expressando valores historicamente preponderantes. (ASSIS, 2004, p. 93).

Acerca da celeridade processual, esta tem sido um anseio que se estende desde 1950, ano em que “[...] a Convenção Européia para salvaguarda dos Direitos do Homem e das Liberdades Fundamentais apresentou preocupação com a duração excessiva dos litígios." (CEZNE, 2006, p. 443).

A fim de tentar encontrar um remédio substancial para sanar a demora na resolução da lide pelo judiciário, prima-se pela observância de alguns princípios essenciais para o bom desenrolar dos processos.

Um desses princípios é o do devido processo legal, sendo que é entendimento de Fredie Didier Júnior, que este é a base de todo e qualquer direito de toda e qualquer pessoa dentro do nosso ordenamento brasileiro devendo ser um processo justo e equitativo (DIDIER Jr., 2015, p. 63).

Aliado a esse novo modelo jurisdicional, o princípio da duração razoável do processo, previsto no art. $5^{\circ}$, inciso LXXVIII, da CRFB, prima pela não morosidade do sistema evitando que as partes saiam lesionadas pelo litígio tendo em vista a demora das ações judiciais.

Assim, um processo para ser célere deve utilizar-se de mecanismos que auxiliem no deslinde processual e por consequência se torne uma lide mais econômica e menos morosa, facilitando o acesso do jurisdicionado ao judiciário. Como consequência, o cidadão criaráexpectativas de ver seus problemas resolvidos de forma mais rápida, econômica e de forma 
eficiente, esse último, previsto no art. 37, caput da CRFB.

Ademais, um processo, no entendimento de Portanova, precisa ser célere e econômico devendo preocupar-se com a eficiência do provimento jurisdicional (PORTANOVA, 2013, p. 27). Assim, percebe-se que de nada adianta um procedimento ser rápido se este não observar premissas de direito fundamental como o contraditório e a ampla defesa.

Dessa forma, verifica-se que o judiciário está em busca de aliar um procedimento mais célere, econômico e que seja eficaz ao mesmo tempo, a fim de evitar qualquer nulidade processual e ferir qualquer direito inerente à pessoa humana, resguardados pela nossa CRFB.

Ressalta-se que no meio judicial, "O processo, para ser devido, há de ser eficiente. O princípio da eficiência, aplicado ao processo é um dos corolários da cláusula geral do devido processo legal.”(DIDIER, Jr., 2015, p. 98, grifo do autor).

Dito isso, é possível verificarmos que é primordial o investimento em tecnologias, sistemas e aperfeiçoamento dos trabalhadores da justiça a fim de que o processo se torne célere, econômico, eficiente e que alcance a eficácia para a qual foi criado, objetivando a proteção das partes envolvidas e de seus direitos inerentes à pessoa humana, resguardados pela Constituição da República Federativa do Brasil.

\subsection{Da penhora de valores por meio online}

$\mathrm{O}$ ordenamento brasileiro adotou como primeira alternativa a fim de garantia da lide a restrição de valores, conforme preconiza o art. 835, CPC, no qual "A penhora observará, preferencialmente, a seguinte ordem: I - dinheiro, em espécie ou em depósito ou aplicação em instituição financeira".

Salientamos que "[...] esta preferência, em determinado 
instante pode parecer racional porque adequada às necessidades sociais e de mercado- pode se tornar defasada com o passar do tempo." (MARINONI; ARENHART, 2008, p. 269).

Considerando o disposto no art. 835, inciso I do Código de Processo Civil, verificamos que o legislador escolheu sabiamente o dinheiro como primeiro bem para garantia da execução uma vez que este apesar das oscilações de mercado, sempre estará no topo das escolhas como melhor meio de satisfação do credor.

Acerca de como eram feitas as buscas por numerário do devedor, inicialmente, para que se fosse possível a efetivação de restrição de valores era necessário o envio de ofício físico ao Banco Central e após recebido o ofício, este realizava a comunicação às demais instituições bancárias a fim de averiguar sobre numerários do devedor. Ressaltamos que naquela época não havia a permissão de inclusão das cooperativas para a efetivação de pesquisas e bloqueios.

Feita a comunicação com as outras instituições financeiras, o Banco Central deveria ainda comunicar o Juízo de origem. Assim, percebemos o quão moroso era o sistema, uma vez que o envio de três ofícios para diferentes órgãos em três etapas de certo consumia um tempo considerável de pelo menos seis meses.

Assim, percebemos que a maneira em que era realizada a busca por numerários do devedor era demorado e prolongava de forma excessiva o processo, facilitando, inclusive, a ocultação de valores pelos inadimplentes.

Apesar desta morosidade, a competência para a consulta de numerários e demais informações resguardadas em ambiente bancário permanece sendo do Banco Central pela força da Lei n. 9.613/98 que trata sobre os crimes de lavagem ou ocultação de bens, direitos e valores, sendo uma forma de prevenção a utilização do sistema financeiro nacional, determinando, em seu art. 
10-A que "O Banco Central manterá registro centralizado formando o cadastro geral de correntistas e clientes de instituições financeiras, bem como de seus procuradores." (BRASIL, 1998).

Pois bem, com o advento da tecnologia e com o intuito de atender aos anseios sociais aliado à economicidade e celeridade processual, aplicou-se novas formas de realização de restrição de valores

Considerando a necessidade de realizar procedimentos mais céleres e eficazes na busca de numerários nas instituições bancárias além de dados pessoais do requerido, instituído o Bacen Jud, por meio do primeiro convênio com o Banco Central, no ano de 2001 na área trabalhista. O mesmo sistema foi estendido para as execuções fiscais no ano de 2005, pela Lei Complementar n. 118/2005 e posteriormente para a justiça comum em 2006.

Com relação à Justiça Comum, como forma de dinamismo necessário a economia e celeridade processual, o executado "[...] não é mais citado para pagar ou nomear bens à penhora. $\mathrm{Na}$ verdade, o executado não tem direito de nomear bens à penhora, mas sim dever de pagar." (MARINONI; ARENHART, 2008, p.268). Por consequência, inadimplente o executado, poderá lhe ser retirado o "[...] valor em dinheiro suficiente para saldar forçadamente a sua dívida, com os devidos acréscimos." (MARINONI; ARENHART, 2008, p.268).

Com a versão eletrônica do sistema, agora a penhora é realizada de forma online. Considerando que é um ato de fase inicial de expropriação de bens, verifica-se que o procedimento “[...] visa, principalmente, a individualização do bem sobre o qual recairá a satisfação do crédito, obtida com a conversão em dinheiro." (MIGLIAVACCA, 2016, [n.p.]).

Dessa forma, o sistema pode ser considerado o meio mais eficaz para garantia da lide uma vez que os outros meios de penhora são demorados e por diversas vezes tornam-se infrutí- 
feros seja por deterioração do bem penhoradoou pela negativa de tentativas de sua venda em hasta pública.

Salientamos que o sistema Bacen Jud não é utilizado apenas para a realização de restrição de valores, nele também é possível averiguar acerca de outras informações pessoais da parte, como por exemplo o seu endereço e contato telefônico. Ressaltamos que por se tratar de transações bancárias, é possível que se encontre telefones e endereços mais atualizados do indivíduo, o que possibilita maior êxito em encontrá-lo e por consequência, garantir o contraditório e a ampla defesa nos autos.

Desse modo, o indivíduo que antes se esgueirava da justiça, poderá mais facilmente ser encontrado por meio do sistema Bacen Jud uma vez que as contas bancárias tendem a serem mais atualizadas do que as de serviços públicos disponíveis para consulta pelo judiciário.

Ademais, "Sendo a penhora de dinheiro a melhor forma de se viabilizar a realização do direito de crédito" (MARINONI; ARENHART, 2008, p. 274), nada mais natural que esteja em destaque na ordem preferencial de penhoras do art. 835 do Código de Processo Civil.

Entendem ainda, Marinoni e Arenhart que, considerando que a penhora de valores dispensa todo e qualquer outro procedimento de adequação de forma, como seriam os casos de outros bens que necessitem de preparação antes de garantirem o credor, essa deve ser priorizara pelo Judiciário e preferível sobre todo e qualquer outro bem. (MARINONI; ARENHART, 2008, p. 274 e 278).

Considerando o anteriormente exposto, o CNJ, que está em constante aperfeiçoamento de técnicas a fim de melhorar a justiça brasileira, apoia o sistema Bacen Jud autorizando o seu uso por meio de convênio firmado com o Banco Central, em 08.12.2008. 
Além do CNJ, há outros convênios firmados por outros órgãos juntamente com o Banco Central, é o caso do Superior Tribunal Federal, Tribunal Superior do Trabalho, Superior Tribunal de Justiça, Superior Tribunal Militar e o Tribunal Superior Eleitoral.

Logo, percebe-se que o sistema Bacen Jud está sendo reconhecido como uma ferramenta de integração entre os órgãos de Justiça brasileiros. Este fato é de suma importância uma vez que a tendência é ter uma integração entre todos os sistemas a fim de colaborar com a busca pela justiça em nosso país.

\subsection{Do sistema Bacen Jud}

Considerando que a restrição de valores feita de forma online através do sistema Bacen Jud, é uma ferramenta célere utilizada pela justiça, é preciso que se tenham alguns cuidados na sua aplicação.

Sobre o tema, o Novo Código de Processo Civil de 2015 é inovador uma vez que traz a permanência da penhora online assim como um capítulo de exposição denominado "Subseção V- Da Penhora de Dinheiro em Depósito ou em Aplicação Financeira." (BRASIL, 2015).

A fim de garantir que a penhora seja efetiva e haja a observância de zelo para que seja realizada de forma correta, há uma ordem de andamento da penhora pelo sistema Bacen Jud a ser seguida onde o Banco Central explica em seu Manual Básico que o primeiro passo é a pesquisa dos ativos financeiros, comando dado pelo Magistrado. Após, a partir das 19 horas, caberá ao Banco Central consolidar todas as ordens, gerando um arquivo de remessa que será transmitido às instituições participantes até as $23 \mathrm{~h} 30 \mathrm{~min}$ do mesmo dia, horário este limitado até as $23 \mathrm{~h} 59$ minutos, cumpridas as determinações judiciais, com exceção de transferência de valores (BANCO CENTRAL, 2015).

Após, caso positiva a busca dos dados requisitados, estes 
se sujeitarão a um processo de validação que será feita até as 8 horas da manhã do dia útil bancário seguinte, quando os arquivos de respostas serão consolidados e transmitidos para visualização do juízo emissor. Com o aporte das respostas disponíveis em tela, o magistrado poderá protocolizar as ordens subsequentes, quais sejam: desbloqueios, transferências, reiteração e cancelamento. Salientando que em ordem de transferência, não há um prazo estipulado, uma vez que se dependerá do trâmite de intimação do executado e decurso do prazo para este se manifestar, e só então poderão os valores constritos serem desbloqueado a seu favor ou do exequente, conforme o caso (BANCO CENTRAL, 2015).

Ressaltamos que, pela celeridade e economia processual por meio do cumprimento imediato do pedido de bloqueio, previne-se a fraude contra a execução e se dá maior segurança ao processamento da demanda.

Ocorre que o sistema é programado para obedecer às ordens judiciais e assim obter informações, bloqueio, desbloqueio e transferência de valores, não fazendo distinção da origem dos numerários constritos, o que pode gerar danos irreparáveis na vida do indivíduo atingido.

\section{DAS IMPENHORABILIDADES IMPOSTAS ÀS RESTRIÇÃO DE VALORES}

A restrição de valores por meio da penhora online demonstra que o judiciário está cada vez mais proativo uma vez que realizada a citação do executado e este deixando transcorrer o prazo in albis, sem oferecimento de manifestação ou deixar de garantir o juízo, o magistrado poderá, a pedido do exequente e independentemente de ciência à parte contrária, solicitar a indisponibilidade dos ativos financeiros existentes em nome do executado.

Solicitada a consulta para restrição de valores junto ao sis- 
tema Bacen Jud, e sendo positiva, o magistrado realizará a penhora sobre o valor cobrado. Ocorre que o Juiz não consegue averiguar a fonte do valor constrito, ou seja, não distingue a origem do provento.

Assim, caberá ao indivíduo acometido da constrição demonstrar se os valores estão abarcados de impenhorabilidade e não estando, garantirão a lide.

Acerca dos valores considerados impenhoráveis, o nosso Código de Processo Civil elencou em seu art. 833 quais seriam esses proventos. Para o presente estudo, é essencial sabermos a seguinte fração do art. 833 do Código de Processo Civil:

Art. 833. São impenhoráveis: [...] IV - os vencimentos, os subsídios, os soldos, os salários, as remunerações, os proventos de aposentadoria, as pensões, os pecúlios e os montepios, bem como as quantias recebidas por liberalidade de terceiro e destinadas ao sustento do devedor e de sua família, os ganhos de trabalhador autônomo e os honorários de profissional liberal, ressalvado o $\S 2^{\circ}$; [...] IX - os recursos públicos recebidos por instituições privadas para aplicação compulsória em educação, saúde ou assistência social; [...] $\mathrm{X}$ - a quantia depositada em caderneta de poupança, até o limite de 40 (quarenta) salários-mínimos; XI - os recursos públicos do fundo partidário recebidos por partido político, nos termos da lei; XII - os créditos oriundos de alienação de unidades imobiliárias, sob regime de incorporação imobiliária, vinculados à execução da obra. [...] § $2^{\circ} \mathrm{O}$ disposto nos incisos IV e $\mathrm{X}$ do caput não se aplica à hipótese de penhora para pagamento de prestação alimentícia, independentemente de sua origem, bem como às importâncias excedentes a 50 (cinquenta) salários- mínimos mensais, devendo a constrição observar o disposto no art. 528, $\S 8^{\circ}$, e no art. 529, $\S 3^{\circ}$. (BRASIL, 2015).

É de suma importância a sua observância, uma vez que detectada a impenhorabilidade sobre determinado numerário, a penhora torna-se ilegal. Assim, "ainda que não haja outros bens do devedor passíveis de serem arrecadados pela execução, os 
bens apontados na regra estão a salvo da responsabilidade patrimonial do devedor." (MARINONI; ARENHART, 2008, p. 260)

Salientamos que o Código de Processo Civil foi inovador ao permitir a penhora sobre salários, apesar de ser uma quantia considerada extravagante para a grande maioria do proletariado brasileiro, entretanto, é um avanço para nosso ordenamento que antes apenas aplicava por meio de analogia para questões de pensão alimentícia.

De fato, é de suma importância que nosso ordenamento preveja a situação em que o salário pode ser penhorado pois $o$ devedor em princípio, procederá ao pagamento de sua dívida por meio de seus proventos e estes possivelmente virão de seu salário. Dessa forma, verificamos que o direito está no caminho de se conseguir balancear a proteção do devedor, uma vez que a execução dar-se-á pelo meio menos gravoso ao executado, mas também deverá objetivar a satisfação dos créditos cobrados.

Essa novidade legislativa trouxe a discussão se haveria uma menor proteção ao executado, contudo, conforme entende Dellore (2015, [n.p]), a atuação dos serventuários da justiça por vezes é frustrada por não ter sido possível encontrar bens passíveis de penhora, e ainda mais frustrante quando encontrados bens, estes são impenhoráveis, desta forma, Dellore (2015, [n.p]) entende que não podem haver excessos tanto no quesito satisfação do exequente quanto proteção do executado, e em todas essas relações, deve prevalecer a proteção do executado para que a situação não lhe fique muito desfavorável.

Existe outra situação que é considerada onerosa ao executado, é a que resulta de uma penhora excessiva. Nesse caso, o magistrado ao efetuar a restrição, não observou todas as contas das quais foram bloqueados os valores e se os mesmos eram suficientes para sanar a dívida e sendo excedentes, deixou de realizar a sua liberação. Desse fato, ao ser intimado, o executa- 
do deverá apresentar uma manifestação comprovando a ilegalidade dos valores constritos.

Além dos bens considerados absolutamente impenhoráveis, ainda temos uma relativização disposta no art. 834 do Código de Processo Civil, que dispõe: que "Podem ser penhorados, à falta de outros bens, os frutos e os rendimentos dos bens inalienáveis." (BRASIL, 2015).

Assim, o bloqueio judicial dos valores obtidos pelo Bacen Jud pode atingir os que são considerados absolutamente impenhoráveis e os relativamente impenhoráveis.

O motivo para que o nosso ordenamento elencasse um rol de valores considerados impenhoráveis está na questão de que são proventos considerados necessários e essenciais para a subsistência do indivíduo atingido pela penhora. Logo, são valores que não são extraordinariamente elevados, são desde pequenas reservas depositadas em poupança que o indivíduo conseguiu ao economizar ao longo de sua vida até mesmo o salário, a aposentadoria dentre outros.

Salienta-se que a execução deve se dar de forma menos gravosa ao executado, conforme dicção do art. 805, caput, em que traz que "quando por vários meios o exequente puder promover a execução, o juiz mandará que se faça pelo modo menos gravoso para o executado.", em contrapartida, além da proteção do executado, o parágrafo único do mesmo dispositivo legal, aprofunda mais a matéria e adianta que caberá "Ao executado que alegar ser a medida executiva mais gravosa incumbe indicar outros meios mais eficazes e menos onerosos, sob pena de manutenção dos atos executivos já determinados." (BRASIL, 2015).

Assim, considerando que a execução se deve dar da forma menos gravosa ao executado ela deve ao mesmo tempo ser capaz dar satisfação à lide. A medida que deve ser aplicada é o encontro de um equilíbrio entre os anseios de ambas as partes, 
para isso, utilizamos como contrapeso o princípio constitucional da dignidade humana.

\subsection{Da penhora de valores perante a aplicação do princípio constitucional da dignidade humana}

O princípio constitucional da dignidade da pessoa humana, conforme entendimento de Garcia e De Lazari, é a base de toda e qualquer interpretação na relação jurídica seja nacional ou internacional, devendo sempre ser levado em conta valores éticos, morais, da justiça e da democracia, ou seja, deve-se sempre ter a dignidade da pessoa humana no foco da situação sendo essa um norte para qualquer interpretação, elaboração e aplicação da norma sendo que a sua inobservância acarreta na própria exclusão de sua personalidade (GARCIA; DE LAZARI, 2014, p. 74-75).

Ademais, a aplicação dos direitos humanos fundamentais exige respeito, devendo ser observada "principalmente pelas autoridades públicas, é pilastra mestre na construção de um verdadeiro Estado de direito democrático" (MORAES, 2002, p. 21).

Tendo em vista a importância de ser observado os direitos fundamentais do indivíduo, o nosso ordenamento aplica o princípio da Dignidade Humana na ponderação de suas decisões. Acerca do tema, entende Soares que este princípio é o responsável pela compreensão e aplicação dos direitos fundamentais do cidadão além de que é um dos principais pilares do nosso direito o qual refletem as estimativas e finalidades as quais o judiciário foi criado aliado aos anseios sociais (SOARES, 2010, [n.p.]).

O sistema Bacen Jud fornece as opções de consulta, bloqueio, desbloqueio e transferência de valores pertencentes ao requerido que se encontrem depositados em contas bancárias, incluindo as cooperativas. 
Antes da reforma do Código de Processo Civil de 2015, as cooperativas estavam fora do acesso do Banco Central para efetivação de penhora de valores uma vez que não era considerada como um banco. Ocorre que o uso das cooperativas se tornou prejudicial ao judiciário uma vez que os indivíduos estavam valendose da condição de não realização de penhoras nas contas existentes naquelas instituições para ocultar numerários de seus credores.

Com a edição do Novo Código de Processo Civil, foi possível aplicar o sistema Bacen Jud nas cooperativas e por consequência coibir ainda mais as fraudes processuais.

Considerando que o sistema não é "inteligente", ou seja, não faz distinção da origem do provento encontrado, exige atenção redobrada do magistrado ou do servidor a ele designado para a realização da busca pelo Bacen Jud.

Assim, verificado o bloqueio em excesso pelo sistema Bacen Jud, deve "[...] o juiz determinar o imediato levantamento da indisponibilidade dos bens ou valores que excederem esse limite." (MARTINS; SCARDOELLI, 2014, p.292).

O descuido da observância da totalidade de numerário bloqueados, gera ônus à parte atingida, ou seja, é uma consequência negativa podendo lhe causar dano excessivo. Essa consequência pode ser visualizada da seguinte maneira: a pessoa havia reservado uma quantia de valor para realizar a quitação de contas de uso rotineiro, como de água e luz, e tendo o valor restringido pelo Bacen Jud, aliado à demora para seu levantamento, uma vez que a demanda de processos no judiciário é deveras crescente, pode acabar tendo consequências negativas em sua vida como o corte do abastecimento de água e luz em sua residência por sua inadimplência.

Atingindo esses bens, configura-se afronta ao princípio Constitucional da Dignidade da Pessoa Humana, sendo que esse ao ser aplicado no presente caso, deve preservar a honra 
dos indivíduos e respeito da forma de vida digna. Ademais, a não observância desses preceitos, apresentará violação da legalidade, da isonomia e do devido processo legal.

Contudo, caso se visualize a observância do contraditório e da ampla defesa, não há o que se falar em ilegalidade da penhora uma vez que houve a chance de o executado demonstrar a sua versão dos fatos e não tendo conseguido caracterizar a impenhorabilidade dos valores, a penhora se torna efetivada.

Além do mais, é visível a importância que se tem em relação a proteção da dignidade da pessoa humana, uma vez que esta está elencada logo no art. $1^{\circ}$, inciso III, da carta magna brasileira, sendo imperiosa a necessidade de sua aplicação e observância:

Art. $1^{\circ}$ A República Federativa do Brasil, formada pela união indissolúvel dos Estados e Municípios e do Distrito Federal, constitui-se em Estado Democrático de Direito e tem como fundamentos:

$[\ldots]$

III - a dignidade da pessoa humana;(BRASIL, 1988).

A criação de normativas que não visualizam a aplicação deste princípio, afrontam a existência normalizadora constituída pela Constituição Federal, devendo ser repensadas e adequadas ao impasse que só assim terá eficácia na aplicação da legislação, em que "na verdade, a jurisdição tem o objetivo de dar tutela às necessidades do direito material, compreendidas à luz das normas constitucionais" (MARINONI, 2006, p.109).

Salientamos que é de suma importância a observância de qual momento processual estamos discutindo, uma vez que, no caso de execução provisória, assumirá, o exequente, a “[...] responsabilidade objetiva por eventuais prejuízos causados ao executado na hipótese de reforma de decisão." (RIBEIRO, 2006, p. 282). Isso ocorre porque o requerido poderá ter outros bens a serem nomeados à penhora, não necessitando que seja 
o dinheiro em espécie, pois, complementa Ribeiro, ainda pode haver recurso por parte do executado pendente de julgamento em que existirá a possibilidade de reforma da decisão que está sendo executada (RIBEIRO, 2006, p. 283).

Dito isso, é necessário que haja uma proteção ao indivíduo, mas esta deve ser adequada e deve abranger tanto os direitos do autor quando do devedor.

Ressalvamos que se a lide existe é fato que o devedor deixou de cumprir com o seu dever e por este motivo houve o ingresso da ação a seu desfavor. Assim, considerando que o autor busca pela satisfação dos créditos cobrados aliado ao fato de que se deve dar de forma menos gravosa ao executado, caberá a este último fornecer elementos que demonstrem que a lide está tomando um curso em que esteja o atingindo de forma negativa, em seu íntimo.

De fato, é um balanceamento difícil de ser realizada, todavia, extremamente necessária uma vez que a sua não ocorrência, gera desabono da confiança que as pessoas leigas possuem do judiciário.

Assim, a medida que deve se faz necessária é a de encontrar um equilíbrio entre os anseios de ambas as partes, para isso, utilizamos como contrapeso o princípio constitucional da dignidade humana.

Nesse sentido, constatamos que a aplicação do sistema é perfeitamente possível sem infringir a dignidade da pessoa humana desde que vislumbre os direitos e deveres das partes, em que o uso da tecnologia para maior celeridade e economia processual, ao violar os princípios inerentes ao indivíduo estes deverão prevalecer sobre a aplicação do sistema, uma vez que o uso da penhora de valores permite uma maior segurança na busca da solução e da eficiência dos litígios que decorrem de inadimplência em nossa sociedade. 


\section{CONCLUSÃO}

$\mathrm{O}$ avanço da tecnologia na área jurídica traz celeridade e economia processual com consequente facilitação no desempenhar das funções por parte dos serventuários da justiça e satisfação por parte dos envolvidos nos litígios. Assim como nas outras áreas do direito, a tecnologia não deixa de ser diferente em sua aplicação, sendo necessária a projeção no caso concreto, ou seja, o seu uso deve estar aliado à razoabilidade e proporcionalidade de cada situação.

Considerando que o ordenamento brasileiro tem sua base norteada em princípios, sendo alguns deles o da celeridade e da economia processual e o do devido processo legal, as inovações levadas à atividade jurisdicionada devem manter esses pilares a fim de evitar qualquer nulidade além de observar os demais princípios constitucionalmente instituídos. Ademais, podemos dizer que esses princípios fomentam o uso da tecnologia de forma aliada ao judiciário a fim de dar maior vazão aos processos.

No caso das penhoras de valores, encontramos questões de suma importância para o desenrolar da lide. Uma delas é a violação na esfera íntima do indivíduo por meio de uma restrição que extrapole o valor cobrado ou que atinja bens considerados impenhoráveis pelo art. 833, do Código de Processo Civil.

Considerando que a penhora é realizada de forma imediata e esta acontecendo de forma indevida, como é o caso de quando há excesso de valor restrito, haverá o afrontando do princípio constitucional da dignidade da pessoa humana.

Ressaltamos que os valores são considerados impenhoráveis pelo propósito de sua origem ou de terem uma destinação de garantidores de uma vida digna. Atingindo estes valores, o indivíduo poderá ter consequências irreversíveis em sua vida uma vez que encontrar-se-á desguarnecido de quantias que contava como certas para seu sustento. 
Apesar disso, devemos reconhecer que a penhora online é facilitadora do deslinde dos autos, uma vez que gera celeridade e economia processual por meio do cumprimento imediato do pedido de bloqueio, prevenindo inclusive a fraude contra a execução e por consequência acarretando em maior segurança ao processo.

Considerando a existência de regramento para que a execução ocorra de maneira menos gravosa ao executado, é necessário fazer um contrapeso das expectativas do credor em ver seus créditos adimplidos e as do executado de ver o seu direito à vida digna ser respeitado.

Como meio, utilizamos do princípio constitucional da dignidade humana para balancear os anseios de ambas as partes e chegar a um esforço comum a fim de garantir a proteção dos envolvidos na hora de executar a lide sem prejuízo do desenvolvimento da vida comum dos indivíduos.

Assim, é preciso que o aplicador do direito ao utilizar o sistema o faça com zelo, coibindo a má-fé e garantindo a proteção dos direitos das partes, pois, alguns atropelos no procedimento, acabam se tornando interferências negativas na vida das pessoas.

Ressaltamos que o uso do Bacen Jud veio ao encontro de anseios sociais pela facilitação e agilidade nos processos judiciais. A inadimplência em nossa sociedade está cada vez mais usual e a população anseia por justiça e maior segurança jurídica. Ocorre que nem todo inadimplente é um inadimplente involuntário, por este motivo, faz-se necessário o uso do sistema com observação do nosso ordenamento jurídico e dos princípios regentes do direito.

Ainda, a população busca pela segurança jurídica e a encontra quando possui confiança no judiciário sendo que para isso, é preciso que todos os aplicadores do direito envolvidos 
façam a sua parte com precaução e utilizem com responsabilidade dos recursos tecnológicos ao seu alcance para garantir uma lide mais justa e equilibrada.

Ademais, a penhora de valores no modo online é a forma mais rápida e segura de se conseguir garantir a lide, uma vez que as outras penhoras existentes, como as de imóveis e de móveis, tendem a serem mais penosas e nem sempre chegam a serem efetivas. Assim, está correta a preferência pela penhora de valores em relação às demais previstas em nosso ordenamento.

Assim, ressaltamos a importância de haver um equilíbrio entre os direitos e os deveres de cada parte nos processos e que o nosso ordenamento está atento a essas mudanças e cada vez mais evoluindo em busca de novas tecnologias que possam facilitar o acesso ao judiciário.

Salientamos que o princípio constitucional da dignidade humana é um basilar essencial para a construção do nosso ordenamento jurídico onde a partir deste trabalho, concluímos ser um direito inerente à pessoa humana.

Ainda, que em uma sociedade democrática de direito, todos possuem direitos e deveres, sendo que a igualdade é construída a partir do respeito pelo Poder Público, dos Entes Privados e de seus iguais, tendo o Estado o dever de resguardar o interesse do povo e do Judiciário de garantir que essa igualdade seja observada.

Dito isso, concluímos que o uso da tecnologia é muito bem-vindo no mundo do judiciário, sendo perfeitamente aceita a penhora de valores pelo sistema Bacen Jud, sendo que esses devem adequar-se às formas de nosso ordenamento jurídico além de observarem os princípios norteadores do direito, em prioridade o princípio constitucional da dignidade humana a fim de que se cumpra o fim para os quais foram criados. 


\section{REFERÊNCIAS}

ASSIS, Araken de. Manual da execução. 9. ed. São Paulo: Revista dos Tribunais, 2004.

BANCO CENTRAL. Convênio Banco Central e CNJ. Disponível em: https://www. bcb.gov.br/content/acessoinformacao/Documents/bacenjud/convenios/convenio CNJ_bacenjud2.pdf. Acesso em: 06 abr.2019.

BANCO CENTRAL. Informações pertinentes sobre o Bacen Jud. Disponível em: https://www.bcb.gov.br/acessoinformacao/bacenjud. Acesso em: 05 abr. 2019.

BANCO CENTRAL. Manual do Bacen Jud. Disponível em: https://www.bcb.gov. br/content/acessoinformacao/Documents/bacenjud/manualbasico.pdf. Acesso em: 08 abr. 2019.

BANCO CENTRAL. Perguntas frequentes sobre o Bacen Jud. Disponível em: https://www.bcb.gov.br/acessoinformacao/legado?url=https:\%2F\%2Fwww.bcb.gov. br\%2Ffis\%2Fpedjud\%2Fasp\%2FFAQ_BACENJUD20.asp. Acesso em: 01 abr. 2019.

BANCO CENTRAL. Regulamento Bacen Jud 2.0. Disponível em: https://www.bcb. gov.br/content/acessoinformacao/Documents/bacenjud/regulamentos/Regulamento-BACENJUD-02abr18.pdf . Acesso em: 01 abr. 2019.

BRASIL. Constituição da República Federativa do Brasil (1988). Brasília, DF, Senado, 1998. Publicado no Diário Oficial da União em 05 de outubro de 2008. Disponível em: http:/www.planalto.gov.br/ccivil_03/Constituicao/Constituicao.htm. Acesso em: 07 abr. 2019.

BRASIL. Lei n 13.105, DE 16 de março de 2015. Novo Código de Processo Civil. Publicado no Diário Oficial da União em 17 de março de 2015. Disponível em: http:// www.planalto.gov.br/ccivil_03/_Ato2015-2018/2015/Lei/L13105.htm. Acesso em: 08 abr. 2019.

BRASIL. Lei n 5.172, de 25 de outubro de 1966. Dispõe sobre o Sistema Tributário Nacional e institui normas gerais de direito tributário aplicáveis à União, Estados e Municípios. Denominado Código Tributário Nacional pelo art. 7 do Ato Complementar n 36, de 13.3.1967. Publicada no Diário da Oficial da União em 27 de outubro de 1996. Disponível em: http://www.planalto.gov.br/ccivil_03/LEIS/L5172.htm. Acesso em: 05 abr. 2019.

BRASIL. Lei n. 9.613, de 03 de março de 1998. Dispõe sobre os crimes de "lavagem" ou ocultação de bens, direitos e valores; a prevenção da utilização do sistema financeiro para os ilícitos previstos nesta Lei; cria o Conselho de Controle de Atividades Financeiras - COAF, e dá outras providências. Publicada no Diário Oficial da União em 04 de março de 1998. Disponível em: http://www.planalto.gov.br/ccivil_03/LEIS/L9613. htm. Acesso em 01 abr. 2019.

CEZNE, Andrea Nárriman. Celeridade, prazo razoável e efetivação do direito à tutela jurisdicional:o caso dos Juizados Especiais Federais. Direito e Democracia: Revista de Ciências Jurídicas, Canoas, v. 7, n. 2, 2006.

DELLORE, Luiz. A penhora do salário no novo CPC. 2015. Disponível em: https:// www.jota.info/paywall?redirect to=//www.jota.info/opiniao-e-analise/colunas/novocpc/a-penhora-do-salario-no-novo-cpc-05102015. Acesso em: 07 abr. 2019.

DIDIER, Fredie Jr. Curso de direito processual civil. 17. ed. São Paulo: Juspodivm, 
2015. v.1.

GARCIA, Bruna Pinotti; LAZARI, Rafael de. Manual de direitos humanos. São Paulo: Juspodivm, 2014.

MARINONI, Luiz Guilherme. Curso de processo civil: teoria geral do processo. São Paulo: Revista dos Tribunais, 2006. v.1.

MARINONI, Luiz Guilherme; CRUZ, Sergio Arenhart. Curso de processo civil III: execução. 2. ed. São Paulo: Revista dos Tribunais, 2008.

MARTINS, Alan; SCARDOELLI, Dimas Yamada. Direito tributário. Bahia: Juspodivm, 2014.

MIGLIAVACCA, Carolina Morais. Penhora de acordo com o código de processo civil. 2016. Disponível em: https://jus.com.br/artigos/53734/penhora-de-acordo-como-codigo-de-processo-civil. Acesso em: 02 maio 2019.

MORAES, Alexandre. Direitos humanos fundamentais: teoria geral. 4. ed. São Paulo: Jurídico Atlas, 2002.

PORTANOVA, Rui. Princípios do processo civil. 8. São Paulo: Livraria do advogado, 2013.

RIBEIRO, Leonardo Ferres da Silva. A execução provisória diante da Lei n.11.232/2005. In: BRUSCHI, Gilberto Gomes. Execução civil e cumprimento da sentença. São Paulo: Método, 2006.

SOARES, Ricardo Maurício Freire. O princípio constitucional da dignidade da pessoa humana: em busca do direito justo. 10. ed. São Paulo: Saraiva, 2010.

Recebido em: 12/04/2019

Aprovado em: 18/07/2019 